\title{
Collective Deliberations and Hearts on Fire: Experiential Knowledge Among Entrepreneurs and Organisations in the Mental Health Service User Movement
}

\author{
Hilda Näslund ${ }^{1}$
}

Published online: 14 May 2020

(C) The Author(s) 2020

\begin{abstract}
Previous research has shown that experiential knowledge plays an important role for service user movements and has also discussed ambiguities in the definition of this type of knowledge. This study contributes to clarifying how experiential knowledge is understood within the service user movement. Through semi-structured interviews, it explores how Swedish mental health service user organisations (MHSUOs) and service user entrepreneurs (SUEs) regard the role of experiential knowledge for their endeavours. The study shows that SUEs and MHSUOs view experiential knowledge as complementary to established medical and expert knowledge. Both groups further reflect on the functions of individual and collective dimensions of experiential knowledge. Emotions are important in conveying experiential knowledge, although emotional commitment can be short-lived. The study discusses challenges for SUEs and MHSUOs in developing strategies to manage risks tied to strategic essentialism, and also in maintaining a critical standpoint towards established service providers.
\end{abstract}

Keywords Mental health - Service user organisation . Service user entrepreneur - Experiential knowledge

Hilda Näslund

hilda.m.naslund@umu.se

1 Department of Social Work, Umeå University, 90187 Umeå, Sweden

\section{Introduction}

Experiential knowledge (Borkman 1976) is a significant topic in current research on mental health issues (Noorani et al. 2019; Pattadath 2016; Voronka 2015, 2016). Prior studies have illustrated that experiential knowledge is important for the organised service user movement and for individuals acting alongside this movement (Barnes 1999; Karlsson 2011; Näslund et al. 2019a, b; Restall et al. 2011). However, ambiguities in the definition of experiential knowledge (Noorani et al. 2019) have also been discussed. Experiential knowledge has come to denote a range of phenomena and can refer to both personal and collectivised knowledge. This article examines the role of experiential knowledge within two distinct expressions of service user movements: on the one hand, the traditional form of mental health service user organisations (MHSUOs), and on the other, the emerging phenomenon of service user entrepreneurs (SUEs) that represent personalised means to engage for change. The service user movement is becoming more diversified through the rise of such personalised expressions. However, experiential knowledge remains central. This motivates exploring the current role of experiential knowledge among collective and personalised expressions.

The aim of this article is to explore how MHSUOs and SUEs regard the role of experiential knowledge for their endeavours. This will be pursued by asking how they employ experiential knowledge and by examining what ambitions are related to this. That will enable a discussion of how different understandings of experiential knowledge involve various political risks and opportunities, in terms of the renegotiation of power relations in the mental health sector.

MHSUOs are formal non-profit organisations that mobilise service users and family members, and these 
organisations were established during the late 1960s in the Swedish context of study (Engman 1992). SUEs is an emerging expression within the field (Näslund et al. 2019b). Often active on social media, SUEs are individuals with lived experience of mental ill health who have established private businesses that organise their involvement in mental health issues. As social entrepreneurs, their businesses balance goals of moneymaking with strives for social change (Näslund et al. 2019b). Experiential knowledge is a vital source of authority for SUEs as well as MHSUOs (Näslund et al. 2019a, b). Given that their organisational form and ambitions differ, SUEs presumably diverge from MHSUOs in how they employ experiential knowledge. Furthermore, experiential knowledge is closely linked to legitimacy claims and is commonly discussed in relation to the knowledge of professionals and authorities (Castro et al. 2019). New forms of mobilisation drawing on experiential knowledge, definitional ambiguities and its pivotal role in carving out a unique knowledge domain, motivate exploring the current role of experiential knowledge in the service user movement. In the following sections, I will position MHSUOs and SUEs on the service user movement field, discuss the growing focus on experiential knowledge within the mental health sector and consider epistemological aspects of knowledge grounded in lived experience.

\section{Organisations and Entrepreneurs}

Service user movements have shifted in form throughout the years. The first expressions were loosely defined networks for self-help and peer support (Brown et al. 2008). Over time, MHSUOs have grown in number and has come to be the primary form of organisation. Such established forms of organisation has been discussed as collective action (Bennett and Segerberg 2012). Many MHSUOs are today engaged in advocacy and provide member support to people with lived experience and their relatives. Previous research has primarily focused on how MHSUOs work towards influencing policies and improving rights for patients (e.g. Funk et al. 2006; Gee et al. 2015; Janzen et al. 2006; Montenegro and Cornish 2019; Rose and Lucas 2007). In the Swedish context, a growing number of diagnosis-specific MHSUOs have been established during the past decades. Swedish MHSUOs are mainly involved in informal peer support at the local level (Markström and Karlsson 2013) and activities relating to systematic advocacy and knowledge dissemination at the national level. These organisations further have close collaborations with and financial ties to government authorities (Näslund et al. 2019a).

Alongside MHSUOs, more individualised expressions of service user engagement have emerged. A general personalisation of politics is echoed in the mental health sector and is reinforced by the growth of social media (Bennett and Segerberg 2013; Johansson 2015; Myndigheten för vårdanalys 2015). SUEs reflect such developments. This burgeoning phenomenon consists of individuals with lived experience that engage in mental health issues through a private company (Näslund et al. 2019b). SUEs give lectures, author books and use social media to communicate with their audiences. Mainly focusing on educational and informational activities, personal narratives of mental ill health and recovery constitute the basis of their authority (Näslund et al. 2019b). SUEs can be discussed as a form of connective action (Bennett and Segerberg 2012) and reflect more personalised forms of mobilisation, with personal reasons for joining a cause in focus and through the employment of personal communication technologies (Bennett and Segerberg 2012). SUEs' platforms are dependent on people engaging with the content produced. Such loosely structured communication networks replace the function of an organisation in connective action (Bennett and Segerberg 2013; Parsloe and Holton 2018). SUEs are often dependent on public sector actors contracting them to for instance give lectures but otherwise have fewer formal connections to the public sector, compared to MHSUOs.

Through their platforms and associated networks, SUEs and MHSUOs can be seen as central loci for social mobilisation. Social movements are 'networks of informal interactions between a plurality of individuals, groups and/ or organisations, engaged in political or cultural conflicts, on the basis of shared collective identities' (Diani 1992, 1). Connections between actors are thus central to social movements (Diani 2003), and MHSUOs and SUEs can be seen as service user movement actors through them engaging in such networks and initiating social movement action. Shared collective identities in SUEs' and MHSUOs' networks can vary, and for some groups connect to identification to a diagnosis-group and for others to the identity of having 'lived experience' of mental ill health. SUEs' and MHSUOs' involvement in political or cultural conflicts can further range from promotion of specific policy reform to rather sweeping ambitions of counteracting stigma in society. MHSUOs represent collective and established forms of mobilisation, and SUEs represent emerging connective and personalised forms of mobilisation, but both expressions draw on experiential knowledge for legitimacy (Näslund et al. 2019a, b). This new situation motivates exploring how this type of knowledge is employed in a new situation. A specific concern relates to how the democratic foundation of MHSUOs and the personal focus of the SUEs impinge on their approaches to experiential knowledge. 


\section{Enhanced Status of Experiential Knowledge}

Borkman (1976, 446) defines experiential knowledge as derived 'from personal experience with a phenomenon'. In contrast to professional knowledge, experiential knowledge is to a greater extent pragmatic, here-and-now oriented and holistic (Borkman 1976). Experiential knowledge is often contrasted with clinical and research-based perspectives (Karlsson and Markström 2013). It includes knowledge of embodied experiences of mental ill health, interactions with support and service systems, and societal attitudes (Castro et al. 2019; Noorani et al. 2019). Experiential knowledge can also be formulated as a collective knowledge, that gains in authority by being shared over time in social movements or collective contexts (Dawney 2013; Noorani 2013). This type of knowledge can further be transferred at different levels, for instance through peer support, involvement in service development and through systemic advocacy directed at policy and legislation (Castro et al. 2019).

The growing recognition of experiential knowledge in the mental health sector (Noorani 2013; Restall et al. 2011) is reflected in the emergence of 'experts-by-experience' (McLaughlin 2009; Noorani 2013) hired to work alongside medical professionals in mental health services (Mayer and McKenzie 2017; Meriluoto 2018), and also in an increased emphasis on 'lived experience' (Rose 2016). It can further be seen in the promotion of service user involvement in research (e.g. Beresford 2003, 2013; Kara 2013; Rose 2014; Telford and Faulkner 2004) and service development (e.g. Omeni et al. 2014; Sweeney and Wallcraft 2010; Thornicroft and Tansella 2005). The struggle of service user movements has contributed to this valorisation, where the historic association of mental ill health and irrationality (Sanati and Kyratsous 2015) has posed specific challenges. However, the so-called 'crisis of representation' triggered a debate on who has the right to speak for marginalised groups, and was followed by a pluralisation of knowledge claims, where speaking from experience gained new status (Voronka 2016). Experiential knowledge can, however, be formulated in different ways and some have described how service user influence is increasingly focused on sharing individual experience (Eriksson 2018). This is reflected in the way service providers today, through employment relationships, can bring in experiential perspectives directly from selected individuals, unaffiliated with service user movements (Alm Andreassen 2018). Both the enhanced status and the developments towards individualisation raise questions about how the role of experiential knowledge plays out among MHSUOs and SUEs.

\section{Debates on Knowledge Grounded in Lived Experience}

The valorisation of experiential knowledge provides a potential for political benefits. Drawing on experiences may be a means to increase the influence of service user collectives in relation to authorities and service providers. However, Voronka $(2015,2016)$ discusses how conceptualising 'people with lived experience' as having access to a specific form of knowledge is also associated with the risks of strategic essentialism. Legitimising service user groups' influence through lived experience and experiential authority could hide how understandings of mental ill health are connected to divergent ideological standpoints within these groups (Voronka 2016). In reply to Voronka (2016), Rose (2016) contends that experiences should be employed to theorise the situations of service user collectives. She further emphasizes the importance of social movement groups for enabling a political analysis of experiences. These positions are important for my analysis as they highlight political risks and opportunities associated with service user groups' articulations of experiential knowledge.

This emerging debate relates to theoretical and political concerns long-discussed in critical scholarship and among standpoint theorists. Knowledge has been discussed as situated, where positionality is important for what one can know (Haraway 1988; Nelson and Nelson 1994). Standpoint theory involves analytical departure from the position of marginalised groups and informs this study by contributing to the analysis of collective dimensions of experiential knowledge. Rather than focusing on individual experience in itself, Harding (2008) discusses how experience can be used to 'study up' the situation of subordinate groups. The strong objectivity (Harding 2004b) that is connected to these groups' positions does not come automatically. It can be obscured by ideology and is developed through political processes of collectively theorising experiences (Harding 2004a). Where the experiences of marginalised groups diverge from hegemonic discourses, a critical standpoint can emerge (Smith 1988).

However, founding theoretical claims on the authority of experience is, according to Scott (1991), problematic for examining how difference is produced. It can cause failure to account for the discursive construction of 'experience' and can risk essentialising social identities. According to Scott (1991), experience does not constitute the foundation of evidence or authority. What gets counted as experience is rather a political process, and it is this process that should be examined. To counter this critique, Stone-Mediatore (2000) argues that experience should not be conceptualised as indisputable evidence, but as embedded in social relations and as a resource for critical reflection. 
Experience provides access to knowledge because of the very fact that 'personal experience' is both social and informed by available theories (Mohanty 2000). This means that what is defined as experience or knowledge is the result of a social process (cf. Nelson and Nelson 1994). Social movement groups in the mental health sector have over time collectivised experiences of mental ill health and recovery. SUEs' and MHSUOs' potential to constitute knowledge communities and form critical standpoints are central to my discussion.

\section{Methods}

In order to pursue the aim of the study, 16 semi-structured interviews (Edwards and Holland 2013) were conducted with eight SUEs and eight representatives of MHSUOs in Sweden. This national context is marked by extensive internet use (Davidsson et al. 2018), giving SUEs the potential to reach large audiences. Furthermore, Sweden has a long tradition of MHSUOs, with close ties to the public sector (Näslund et al. 2019a). A previous mapping study of the 14 MHSUOs operating in Sweden (Näslund et al. 2019a) was central to the sampling for this study. The field of Swedish MHSUOs is diverse with regard to the organisations' size and target groups (Näslund et al. 2019a). Large, mid-size and small organisations were included. Both MHSUOs that are focused on specific diagnosis groups and those with a broader definition of their target group were selected. Eventually, eight organisations were represented. Interviewees were central representatives, such as CEOs or operations managers, with a good overview of organisational activities.

For the SUEs, data collection was entangled with the process of defining the phenomena. Through an initial survey of the field, several examples of people who communicate their lived experience of mental ill health through a private business were identified. Some of these were social media influencers, in part focusing on mental health issues, still others were self-employed 'recovery consultants'. To further delimit the phenomena, only examples where mental health constitutes the core concern and where experiences were communicated to a general public were included. SUEs were defined as individuals who "(1) have founded a company, (2) share their individual narratives of mental health in the company and (3) have the aim of reaching a public audience" (Näslund et al. 2019b, 3). Individuals who are employed by mental health services to provide experiential perspectives but who have not established private businesses (Alm Andreassen 2018; Eriksson 2019) were thus excluded. Two distinct groups of SUEs were identified: those mainly active on social media and those primarily involved in educational activities in other arenas. In order to showcase variation within this phenomenon, the sampling strategy was to include SUEs from both these groups. Eight SUEs were included in total. Relationships between SUEs and MHSUOs are common. Some entrepreneurs have close connections to MHSUOs, for instance as board members or part-time employees. Especially SUEs mainly active on social media report fewer formal connections, limited to dialogues and collaborations with MHSUOs on specific issues.

I used interview guides that focused on the development, issues in focus, relationships to external actors and activities of MHSUOs and SUEs. The interview guides further had a specific focus on the role of experiential knowledge, by probing for how it is employed and communicated, what constitutes its basis, how this type of knowledge relates to other knowledge sources, and if its status has developed over time. Informed consent was obtained, all information has been anonymised, and the interviewees were given the opportunity to comment on the results of the study prior to publication. The study received approval from the Regional Ethical Review Board in Umeå: 2016/121-31. The interviews (lasting 40-120 min) were transcribed verbatim, but quotes have in presentation been slightly adapted to written format to facilitate reading.

Directed content analysis (Hsieh and Shannon 2005) was applied to analyse the interviews and experiential knowledge was used as a guiding concept for the analysis. The choice of attending to experiential knowledge was made deductively, based on prior research in the area (e.g. Grim 2019; Näslund et al. 2019a, b; Noorani et al. 2019). Initially, relevant quotes were grouped in relation to their content. Through constant comparisons of quotes, analytical categories and themes were constructed. A panel consisting of members with lived experience of mental ill health or as relatives, trained in basic research methods, examined and consulted on the analysis. The panel at large confirmed the preliminary analysis as coherent with their own experiences, but stressed the importance of regarding SUEs' and MHSUOs' roles in the mental health sector as complementary, which was considered in the analysis. The themes 'Capacities of experiential knowledge' and 'Developments of experiential knowledge' (Table 1) are described in the following section. The interviewees have been numbered to attribute quotations and provide transparency in data.

\section{Results}

In this section, I discuss central tendencies in how SUEs and MHSUO representatives regard the role of experiential knowledge for their endeavours, to specifically discuss how these actors employ experiential knowledge and what 
Table 1 Overview of themes, underlying categories and exemplary quotes

\begin{tabular}{lcc}
\hline Theme & Category & Exemplary quote \\
\hline $\begin{array}{l}\text { Capacities of experiential } \\
\text { knowledge }\end{array}$ & $\begin{array}{c}\text { Emotional } \\
\text { narratives }\end{array}$ & $\begin{array}{c}\text { It's not possible to understand these processes, what's difficult and what one can feel, without } \\
\text { a detailed narrative that is personal }\end{array}$ \\
& $\begin{array}{c}\text { Collectivising } \\
\text { experiences }\end{array}$ & [I]n the meeting with many others, one plus one equals three... That's to say, you see more \\
things and become wiser
\end{tabular}

ambitions are related to this. These tendencies are explored in relation to two themes: 'Capacities of experiential knowledge' and 'Developments of experiential knowledge' (see Table 1). The first refers to how different articulations of experiential knowledge can achieve change. In this regard, two aspects are highlighted: the capacities involved in personal narratives and the capacities of collectivised experiences. The second theme deals with perceived developments over time. It refers to views on how articulations of experiential knowledge have evolved in relations to its status, its position in relation to other knowledge sources and in terms of moves towards more generalised articulations.

\section{Capacities of Experiential Knowledge}

Interviewees describe how service user movement actors employ both individual and collective articulations of experiential knowledge. They further connect these articulations to different capacities in mobilising for change. Interviewees from both groups describe how personalised and collectivised experience serve different functions and need to complement each other. Personal narratives are articulated with the ambition to provide in-depth and contextualised information, which activate emotional processes that has the capacity to support engagement for change. Collectivised experiences are associated with other ambitions, by giving give force to the information shared. Through their extended representativeness, they have the capacity to be employed for service and policy development.

\section{Emotional Narratives}

Personal narratives of mental ill health and recovery are vital to both MHSUOs and SUEs, because they activate emotions that are important in order to mobilise for change. Representatives of MHSUOs describe the central function of personal narratives in enabling an in-depth understanding of mental ill health: 'It's not possible to understand these processes, what's difficult and what one can feel, without a detailed narrative that is personal.' [MHSUO representative 1]. Giving concrete examples, through narratives with emotional appeal, is seen as central in the process of transferring experiences:

I try to move people. Here's my belief, if I talk for two hours and manage to make someone feel a bit discouraged or even shed a tear... or if I make people laugh, if feelings emerge in the audience, in that case I think that the knowledge will stick better. So, I try to stir up some feelings. SUE 8

Motivation for change among actors within the movement and in external actors is seen as dependent on people having an emotional commitment to these issues. Prior research (e.g. Jacobsson and Lindblom 2013; Jasper 2011) has similarly described how emotions are employed in social movements with the ambition to mobilise and work up engagement. Interviewees describe how the emotional appeal of personal narratives promote empathic imagination in audiences, which in turn may initiate reflection and potentially change in attitudes:

[T]o mobilise change... for actually doing something different in one's practice, based on one thinking:

"Shit, what am I doing?" or "Oh, can this be 
perceived this way? Is there something that I can do to change that?"... [T]o change oneself you sometimes need to be shaken to the core. And if I can do that through examples of things I've experienced, I want to do that. SUE 5

For MHSUOs, personal narratives are employed in advocacy work with the ambition to demonstrate that policy decisions concern more than numbers in columns, and affect the actual lives of people:

I believe that in order to change attitudes... you need other peoples' narratives... In order for me to... think: "What if this were to happen to me? What would that be like?" For that, a face and a narrative that I can process through the gut and not through the brain is required... And that's an element we need to work on in these endeavours. Because when we meet officials in county councils, these people also need to be helped to want to reflect and think that maybe I haven't understood all of this. To have that humility in oneself. MHSUO representative 4

Interviewees discuss how these narratives initiate processes of identification and demonstrate the need for services to include the knowledge of people with lived experience. The emotional processes that are activated by personal narratives are thus employed with the ambition to mobilise engagement at a personal level, within service user groups, and also in external actors.

\section{Collectivising Experiences}

Both groups, but especially MHSUO representatives, emphasize the collective nature of how experiential knowledge is articulated. The employment of collective articulations is described as connected to other capacities than personal narratives, by increasing the credibility and impact of the experiential knowledge. Collectivised experiential knowledge can thereby be drawn upon with the ambition to influence services and policies.

SUEs collect information from a vast number of individuals through interactions with their audiences, especially on social media. As a result, they gain insights into the health of others, enabling them to discern patterns in what people experience as difficult or helpful. Interviewees from MHSUOs often emphasize the collective dimensions of experiential knowledge. They highlight how individual knowledge converges with the knowledge of peers, thus becoming something more: '[I]n the meeting with many others, one plus one equals three... That's to say, you see more things and become wiser' [MHSUO representative 3]. The merging of experiences of many is described to come closer to a truth about the situation for people with experiences of mental ill health. Peer support within organisations is seen as the primary way of gathering experiential knowledge from members:

It's that we meet and comfort each other. It's in the support between people with similar experiences that you discover things: "Did that happen to you? Is it still like that at that clinic? Haven't they gotten any better?" I believe that's the most common and important way to capture [experiential knowledge] that happens all the time. MHSUO representative 4

This process can be related to ambitions of developing meaning perspectives (Noorani et al. 2019) through collective processes of theorising experiences. In discussing relationships between MHSUOs and SUEs, representatives of the former raise concerns regarding representativeness. Representing more people lends weight to the experiences that are expressed, and the large knowledge base of the organisations is thus stressed. To them, it is important that speakers representing the organised service user movement recognise that they are actually representing the experiences, opinions, and knowledge of a greater collective. They further stress the importance of acknowledging that individual perspectives are partial and need to be supplemented with the perspectives of others. The interviewees from MHSUOs argue that personal narratives and collectivised knowledge are most effective together and that they are employed with different ambitions. However, their functions are tied to different kinds of representativeness, especially in relation to service and policy development:

Even though we have to be clear in saying that a lecturer that sets the heart on fire and gets people to change their attitudes isn't somebody you can consult on long-term issues, on what we should think about psychiatry. Then you need another collaboration. But we also need those more vivid narratives. And that's also a way to disseminate, to use self-experienced knowledge... But that's another kind. We use selfexperienced knowledge... in another way, so we also have to organise differently. It's not just about sparking narratives, we also need tedious and sustained work, so to speak. MHSUO representative 4

In relation to these varying kinds of representativeness, MHSUOs are founded in processes of democratic decisionmaking, that give their articulations of experiential knowledge the capacity to be included in policy processes. These issues are discussed as problematic when public sector actors fail to understand what kind of experiential knowledge and representativeness is needed in different arenas. 


\section{Developments of Experiential Knowledge}

The interviewees perceive that the articulations, but also the status, of experiential knowledge has developed over time. Many interviewees observe how experiential knowledge has achieved enhanced status within the mental health sector and report increased demand for this type of knowledge from the service system. However, having lived experience can still to this day also challenge legitimacy. MHSUO representatives and SUEs describe how experiential knowledge is employed as a complement to other knowledge sources and a move towards more general themes. Even though emotionally loaded personal narratives are commonly seen as a ground for mobilisation, there are ambitions of moving towards something less 'spectacular'. MHSUOs are described to be involved in processes where experiential knowledge becomes aggregated.

\section{Double-Edged Legitimacy}

Both groups describe a current complexity around the enhanced status of experiential knowledge. Several report a stronger demand from public sector actors, but that the status of experiential knowledge remains double-edged, since it can strengthen but also challenge legitimacy. MHSUO representatives perceive an increased demand for experiential knowledge: “[W]e've become more accepted in the sense that this experiential knowledge is more in demand today." [MHSUO representative 6]. Including the experiences of service users was in the past an exception but interviewees describe how it is rather expected today. To represent experiential, rather than professional, perspectives is also understood to be important for the SUEs' legitimacy and ambition to attract audiences:

[T] he feedback I get is about people thinking: "Great that you've experienced this yourself, since it makes one take note of what you say in a completely different way"... If I hadn't experienced this, people would probably have thought: "Well, why should we listen to him?" So, I'd like to suggest that, at least in my case, it's what's crucial for my business. SUE 8

Interviewees discuss how the current situation is marked by greater legitimacy of experiential knowledge. However, many describe the employment of experiential knowledge as affected by remaining differences between theory and practice surrounding these issues. Such discrepancies might even be more pronounced today, given the promotion of service user involvement in policy documents and withstanding barriers to implementation in practice (Lewis 2014; Storm and Edwards 2013). MHSUO representatives and SUEs are invited to different arenas to share their knowledge, but perhaps on different terms than for professionals. One of the SUEs report such tendencies:

[Y]ou have an entire day about for instance personcentred care and you invite researchers and clinicians, and so on. And then you have a small section where you have like, my narrative. And then you have a short patient narrative, that always looks the same and, well you don't put high demands on it. [I]n some way it should... be included and it often gets a shorter time slot and it's supposed to look a certain way. And sometimes you have to be happy even to be paid, because everyone else get salaries, but you're supposed to be happy just for being chosen. If it's a panel debate, it can be like, you stand furthest out and... aren't expected to contribute to change processes, but only contribute with your own perspective... Like respond to direct questions, and then you're no longer needed. Then, the like 'real people' will make decisions, and they think that they have considered the participation issue and the involvement issue by asking you some questions. SUE 5

Several interviewees perceive an expectation to be grateful for having been listened to. Their participation is at times tokenistic (cf. Arnstein 1969). Their presence is valued based on authorities' ambitions to 'check the participation box', but they are excluded from actual processes of decision-making. Several SUEs report a common separation between experiential and clinical perspectives, where experiential knowledge can strengthen but also challenge legitimacy:

[I]t may bring greater credibility that you're talking from an inside perspective, that you actually have that. But it doesn't have to be like that at all, it can actually even do the opposite. And I believe that's the reason... that those who work clinically may not say that they have a diagnosis themselves. That has to do with credibility. That it can go that way too. SUE 7

Becoming associated with lived experience can according to a number of SUEs make people think that the personal narrative is the only contribution and area of competence. Some SUEs further argue that only certain types of experiences are encouraged. Only particular diagnoses are frequently included, and narratives need to be neatly structured, not too critical of services and to focus on positive outcomes. Patterns similar to these have also been discussed in prior studies on storytelling in the mental health sector (Costa et al. 2012, 89; Eriksson 2013). Even though the interviewees perceive that the status of experiential knowledge is tending to increase, stigma against people with lived experience still exists even within the movement. Some describe how people with lived 
experience are not given access to certain positions within some MHSUOs. Lived experience is thus seen as a risk element, rather than a resource.

\section{Merging Knowledge Sources}

Historically, service user movements have seen experiential knowledge as an alternative and challenge to established medical knowledge (cf. Adame and Knudson 2007). The interviewees of this study do, however, describe how knowledge from research, professional practice and lived experience is now employed with ambitions of them complementing each other. Such a development towards a more consensus-oriented position of experiential knowledge has also been discussed in prior studies (e.g. Näslund et al. 2019a, b). One of the SUEs depicts how he today includes knowledge from different sources in his work:

Maybe I saw psychiatry more as an opponent in the beginning. And in certain regards I still kind of do... But I've become a bit more, well try to bring in... more perspectives and listen to what the driving forces look like there... To try to get all perspectives on it to get closer to some kind of truth and get people who work with these issues and patients and others to get different perspectives. Simply to understand the issue better. Briefly put, I've gone from a pure patient perspective that I thought was very important and which remains important but which in some way has gotten more attention also without my help. To seeing more of an overall picture. SUE 3

Collaboration and co-production becomes a focal point (cf. Alm Andreassen 2018), where different perspectives by the interviewees are seen as complementary. SUEs for instance describe an ambition to increase their collaboration with researchers and authorities, where different areas of competence can supplement each other. Within MHSUOs, relationships to authorities and the mental health service system are often discussed in terms of quality development, where incorporating the experiences of the end user becomes important. Including different perspectives is understood to enable a more exhaustive understanding of mental ill health:

It's like the last piece of the puzzle if you want to see the complete picture... [H]ow can we make it as good as possible for these people? Then you can use the profession to a certain extent, and research to a certain extent, but self-experience... counts for equally much. And to see it... like a part of putting together this complete picture. MHSUO representative 7

In order for this, it is seen as crucial to have a willingness to explore each other's perspectives. Intersections of different knowledge sources can also enable working together as a team:

I think that the very best will come out of us working together and being open with respect to having different perspectives and different knowledge. And not having to see that as a threat. It's not a threat to include the service user movement. And it's not a threat to work with psychiatry. Rather, we work together. MHSUO representative 2

The interviewees thus discuss how experiential knowledge today is being employed with ambitions of complementing other knowledge sources. This seems to be in line with previous findings of a development towards consensus-oriented MHSUOs (Karlsson and Markström 2013). The corporatist tradition (Rothstein 1992), that creates arenas for collaboration based on the voluntary sector's generous access to public policy processes, may impinge on articulations of experiential knowledge as complementary to other knowledge sources in the Swedish context.

\section{Moves Towards Generalisation}

A development towards more generalised knowledge is described within both groups. This is visible in the SUEs that are starting to focus more on broader themes and the MHSUOs that are developing systematic models for finding aggregated patterns in members' experiences. Some entrepreneurs perceive that the supply of personal narratives today has exceeded its demand, causing a current saturation in patient perspectives. In response to this, several recount shifting the focus from sharing their personal narratives to presenting information on general and structural issues. SUEs describe having a desire to not have to be spectacular or that their narrative should be in focus. They express an ambition to gain more substantial influence without having to appeal to emotions. Some take the initiative to incorporate more general themes in their activities, even when their customers have not made such requests. SUEs further describe a development from focusing on 'opening up' the dialogue around mental ill health, towards specific political issues. Several entrepreneurs want to highlight their range of competencies:

[I]t feels like you're welcome because you're selfexperienced and I want to move on and be something other than that. And it's difficult. I want to use it as a stepping stone to get a response... Not like... that's all you have - I also have an education [and] work experience $S U E 5$

Some SUEs also talk about the importance of supplementing personal narratives with aggregated patterns in service users' experiences. A similar ambition to be more 
systematic in collecting and compiling the experiential knowledge of members is also reported by MHSUO representatives: "But if we ourselves think that it's a knowledge on which to build organisations, then we may have to become a bit more careful in how we harness it, and how we make it into knowledge." [MHSUO representative 4]. They describe how the organised movement faces challenges in how to aggregate data from local levels in order to identify national patterns. One MHSUO representative describes how methods for this need to be developed:

[I]t will also enable a stronger voice for us nationally. When we can say with authority... that... in service user inquires that are carried out by the service user movement or people with lived experience, we can see these trends over the last few years... But we really can't do that to a large extent yet. We can... point things out based on common sense. Which really isn't bad of course. But I believe that we could reach further. MHSUO representative 4

Some organisations are starting to employ systematic methods for structuring and aggregating members' lived experiences. Through that, the organisations have the potential to in addition draw on more positivist notions of knowledge. MHSUO representatives argue that being able to compile such aggregated patterns in members' knowledge can potentially give the organisations a stronger voice in relation to authorities.

\section{Discussion}

Previous sections have dealt with the role of experiential knowledge for the endeavours of the organised service user movement and among service user entrepreneurs. The analysis has revealed nuances in how personal narratives are employed with ambitions to capacitate emotional commitment. It has further illustrated how collective articulations are employed with ambitions of them feeding into discourses of service and policy development. Moreover, the interviewees have described how their employment of experiential knowledge and related ambitions have developed over time. This type of knowledge has gained an increased while still unstable legitimacy and is currently employed with ambitions to complement other knowledge sources. Furthermore, a personal focus is merged into more general themes and aggregated knowledge, based on ambitions to reach more substantial influence. With these results as my outset, I will now discuss the benefits and risks of regarding experiential knowledge as a separate knowledge base; different ways of understanding the role of emotions in transferring experiential knowledge; and the relation between collective and individual dimensions in articulations of experiential knowledge.

\section{A Separate Knowledge Base?}

Both SUEs and MHSUOs regard experiential knowledge as a unique knowledge domain and describe their endeavours to strengthen the legitimacy of experiential knowledge. Strategically using knowledge grounded in lived experience can be a way of gaining access and voice in relation to service organisations and systems of knowledge production (Voronka 2016). This may serve to support democratisation of research, policymaking and service provision. But there are also concerns associated with conceptualising lived experience as a specific form of knowledge, inaccessible to others. It can lead to experiences and identities that can be transitory, being seen as essential to a social group (Voronka 2015) and, under the value-neutral label of 'experiential knowledge', hide the diversity of ideological positions within service user collectives (cf. Voronka 2016). This is confirmed by my interviewees, who report tendencies to become tied to the identity of having lived experience. In order to avoid essentialising identities, collectives can highlight non-essentialist connections related to common needs for political change (Siebers 2006) or historical processes of subordination (cf. Mansbridge 1999), making it a political decision to theorise experiences together.

Castro et al. (2019) discuss how experiential knowledge is commonly viewed as complementary to other knowledge sources. In accordance with this, both MHSUO representatives and SUEs regard different knowledge sources as complementary and describe how they strive to include clinical and research-based perspectives in their activities. In this way, many social movements focused on health inhabit hybrid positions, claiming authority through both specialist and experiential knowledge (Brown et al. 2004; Moreira et al. 2014; Rabeharisoa et al. 2014). Such intersections of knowledge perspectives can contribute to a more comprehensive understanding of mental health issues and enable broader collaborations (Tritter and McCullum 2006). But as previously discussed, forming a critical standpoint depends on marginalised groups examining how their experiences diverge from hegemonic discourses (Smith 1988). Close alignment with hegemonic institutions and associated knowledge domains could thus risk limiting the ability to form a critical standpoint based on collectively theorised lived experiences.

\section{Influence Through Emotions}

Storytelling is central to a range of social movements and has been employed as a strategy to counter hegemonic 
discourses (Polletta 1998; Voronka 2015). Such practices are also central to the SUEs and MHSUOs of this study. The activation of emotions, through sharing personal narratives, is seen as an important tool for both SUEs and MHSUOs to mobilise for change. However, SUEs describe becoming tired of narrating their own experiences and acquiring a desire to gain influence without having to appeal to emotions. As a core result, this study shows that emotions are important in the process of articulating and transferring experiential knowledge, but that emotions can be treacherously transient. Emotions do induce commitment. But such emotional commitment can, especially in external actors, be short-lived and need to be turned into more persistent structures for change.

Critics have argued that service user narratives risk being co-opted (Eriksson 2015; Selznick 1949) by service systems, since those who position themselves in alignment with professional views are more likely to be invited (Costa et al. 2012). Further concerns relate to the sharing of personal narratives in arenas that are not service user exclusive. These narratives risk being turned into 'disability tourism' or 'patient porn' (Costa et al. 2012), providing voyeuristic glimpses into intimate and emotional matters, without any substantial transference of power taking place. Sharing personal narratives in peer-support groups holds a more radical potential where collectivised experiences can be used to theorise social relations. It is important for further research to explore how personal narratives can be protected from co-optation and be constituted as political knowledge that highlights social inequalities.

\section{Individual and Collective Knowledge}

Experiential knowledge currently denotes a range of phenomena: from everyday individual stories, to celebrity testimonials, to survivor research and social movements' employment of illness narratives (Noorani et al. 2019). Prior research differentiates between individual and collectivised experiential knowledge (Castro et al. 2019). In this study, SUEs and MHSUOs regard experiential knowledge as comprised of both these dimensions. The activities of SUEs take more personalised forms, but they have also at times created arenas for developing knowledge communities. MHSUO representatives describe the importance of individual experiences, but mainly emphasise these organisations' democratic processes and collective knowledge base. Noorani et al. (2019) present the concept 'deep experiential knowledge'. This refers to knowledge developed in collective contexts, by continually reflecting on one's own experiences and learning from the experiences of others. Where solely personal experience can lead to overgeneralisation, deep experiential knowledge is based on the integrated experiences of many, uncovering patterns of differences and similarities. Even though collective processes of knowledge articulation are most evident in MHSUOs, there is also a potential for deep experiential knowledge in the endeavours of SUEs. Lacking democratic processes, the representativeness of SUEs is, however, not extended to the opinions of larger collectives of service users. As demand for experiential knowledge grows stronger, it is important to clarify what kind of experiential knowledge is needed in different arenas, and which actors are best suited to represent it.

\section{Concluding Remarks}

This study builds on previous research that has explored the central function of experiential knowledge for service user movements. Due to a limited number of SUEs operating in the Swedish context, broad inclusion criteria were applied. A more homogenous group of SUEs might have resulted in a more clear-cut distinction of the groups and of their approaches to experiential knowledge. Moreover, the study proceeds from the perspectives of a limited number of interviewees in Sweden. Further research comparing these results to the situation in other national contexts is required. There is also a need to investigate the mechanisms in how authorities, audiences and the wider public understand the experiential knowledge of SUEs and MHSUOs.

This study has shown that SUEs and MHSUOs regard their employment of experiential knowledge as complementary to medical and other expert forms of knowledge. The personal narratives of SUEs are important for enabling emotional commitment to change. But emotions can be fleeting and the move of many SUEs from emotional personal narratives towards a more general focus is a core finding of the study. The study also provides insights into the relation between individual and collective dimensions of experiential knowledge. To the extent that individual experience takes precedence over collective knowledge, the development here reflects a general tendency in society with increasingly individualising political agendas. The results further suggest the need for SUEs and MHSUOs to manage risks connected to strategic essentialism and underscores the importance of protecting service user groups' ability to form a critical standpoint.

Acknowledgements Open access funding provided by Umeå University. This work was supported by the Swedish Research Council for Health, Working Life and Welfare under Grant (No. 2015-00414).

Open Access This article is licensed under a Creative Commons Attribution 4.0 International License, which permits use, sharing, adaptation, distribution and reproduction in any medium or format, as 
long as you give appropriate credit to the original author(s) and the source, provide a link to the Creative Commons licence, and indicate if changes were made. The images or other third party material in this article are included in the article's Creative Commons licence, unless indicated otherwise in a credit line to the material. If material is not included in the article's Creative Commons licence and your intended use is not permitted by statutory regulation or exceeds the permitted use, you will need to obtain permission directly from the copyright holder. To view a copy of this licence, visit http://creativecommons. org/licenses/by/4.0/.

\section{References}

Adame, A. L., \& Knudson, R. M. (2007). Beyond the counternarrative-Exploring alternative narratives of recovery from the psychiatric survivor movement. Narrative Inquiry, 17(2), $157-178$

Alm Andreassen, T. (2018). From democratic consultation to useremployment: Shifting institutional embedding of citizen involvement in health and social care. Journal of Social Policy, 47(1), 99-117.

Arnstein, S. R. (1969). A ladder of citizen participation. Journal of the American Institute of Planners, 35(4), 216-224.

Barnes, M. (1999). Users as citizens: Collective action and the local governance of welfare. Social Policy \& Administration, 33(1), 73-90.

Bennett, W. L., \& Segerberg, A. (2012). The logic of connective action. Information Communication \& Society, 15(5), 739-768.

Bennett, W. L., \& Segerberg, A. (2013). The logic of connective action-Digital media and the personalization of contentious politics. New York: Cambridge University Press.

Beresford, P. (2003). User involvement in research: Exploring the challenges. Nursing Times Research, 8(1), 36-46.

Beresford, P. (2013). From 'other' to involved: User involvement in research: An emerging paradigm. Nordic Social Work Research, $3(2), 139-148$.

Borkman, T. (1976). Experiential knowledge-A new concept for analysis of self-help groups. Social Service Review, 50(3), 445-456.

Brown, L. D., Shepherd, M. D., Wituk, S. A., \& Meissen, G. (2008). Introduction to the special issue on mental health self-help. American Journal of Community Psychology, 42(1-2), 105-109.

Brown, P., Zavestoski, S., McCormick, S., Mayer, B., MorelloFrosch, R., \& Altman, R. G. (2004). Embodied health movements: New approaches to social movements in health. Sociology of Health \& Illness, 26(1), 50-80.

Castro, E. M., Van Regenmortel, T., Sermeus, W., \& Vanhaecht, K. (2019). Patients' experiential knowledge and expertise in health care: A hybrid concept analysis. Social Theory and Health, 17, 307-330.

Costa, L., Voronka, J., Landry, D., Reid, J., Mcfarlane, B., Reville, D., et al. (2012). "Recovering our stories": A small act of resistance. Studies in Social Justice, 6(1), 85-101.

Davidsson, P., Palm, M., \& Melin Mandre, ̊. (2018). Svenskarna och internet 2018 from Internetstiftelsen i Sverige. Retrieved May 27, 2019 from https://internetstiftelsen.se/docs/Svenskarna_och_ internet_2018.pdf.

Dawney, L. (2013). The figure of authority: The affective biopolitics of the mother and the dying man. Journal of Political Power, $6(1), 29-47$.

Diani, M. (1992). The concept of social movement. The Sociological Review, 40(1), 1-25.

Diani, M. (2003). Introduction: Social movements, contentious actions, and social networks: 'From metaphor to substance'? In
M. Diani \& D. McAdam (Eds.), Social movements and networks: Relational approaches to collective action (pp. 1-18). Oxford: Oxford University Press.

Edwards, R., \& Holland, J. (2013). What is qualitative interviewing?. London: Bloomsbury Publishing.

Engman, T. (1992). Ett sätt att leva: Psykiatri-samhälle: RSMH, en klientrörelses tillkomst och framväxt. Stockholm: Carlssons.

Eriksson, E. (2013). To tell the right story: Functions of the personal user narrative in service user involvement. Journal of Comparative Social Work, 8(2), 251-281.

Eriksson, E. (2015). Sanktionerat motstaind: Brukarinflytande som fenomen och praktik. Lund: Lunds universitet.

Eriksson, E. (2018). Incorporation and individualization of collective voices: Public service user involvement and the user movement's mobilization for change. VOLUNTAS: International Journal of Voluntary and Nonprofit Organizations, 29(4), 832-843.

Eriksson, E. (2019). Den egna erfarenhetens marknad: Om brukarinflytandearbete och kommodifiering av individers erfarenheter av psykisk ohälsa. Sociologisk Forskning, 56(2), 85-109.

Funk, M., Minoletti, A., Drew, N., Taylor, J., \& Saraceno, B. (2006). Advocacy for mental health: Roles for consumer and family organizations and governments. Health Promotion International, 21(1), 70-75.

Gee, A., McGarty, C., \& Banfield, M. (2015). What drives systemic mental health advocates? Goals, strategies, and values of Australian consumer and carer advocacy organizations. SAGE Open, 5(4), 1-8.

Grim, K. (2019). Legitimizing the knowledge of mental health service users in shared decision making: Promoting participation through a web-based decision support tool. Falun: Dalarna University.

Haraway, D. (1988). Situated knowledges-The science question in feminism and the privilege of partial perspective. Feminist Studies, 14(3), 575-599.

Harding, S. (2004a). Introduction: Standpoint theory as a site of political, philosophic, and scientific debate. In S. Harding (Ed.), The feminist standpoint theory reader: Intellectual and political controversies (pp. 1-16). New York: Routledge.

Harding, S. (2004b). Rethinking standpoint epistemology: What is "strong objectivity"? In S. Harding (Ed.), The feminist standpoint theory reader: Intellectual and political controversies (pp. 127-140). New York: Routledge.

Harding, S. (2008). Sciences from below: Feminisms, postcolonialities, and modernities. Durham: Duke University Press.

Hsieh, H.-F., \& Shannon, S. E. (2005). Three approaches to qualitative content analysis. Qualitative Health Research, 15(9), 1277-1288.

Jacobsson, K., \& Lindblom, J. (2013). Emotion work in animal rights activism: A moral-sociological perspective. Acta Sociologica, 56(1), 55-68.

Janzen, R., Nelson, G., Trainor, J., \& Ochocka, J. (2006). A longitudinal study of mental health consumer/survivor initiatives: Part 4-Benefits beyond the self? A quantitative and qualitative study of system-level activities and impacts. Journal of Community Psychology, 34(3), 285-303.

Jasper, J. M. (2011). Emotions and social movements: Twenty years of theory and research. Annual Review of Sociology, 37, $285-303$.

Johansson, A. (2015). Politisering av det personliga. Om sociala medier och mobiliseringen kring psykiatriska frågor. In E. Carlsson, B. Nilsson, \& S. Lindgren (Eds.), Digital politik: Sociala medier, deltagande och engagemang (pp. 67-90). Göteborg: Daidalos. 
Kara, H. (2013). Mental health service user involvement in research: Where have we come from, where are we going? Journal of Public Mental Health, 12(3), 122-135.

Karlsson, M. (2011). Mobilisering genom självhjälpsgrupper. In V. Denvall, C. Heule, \& A. Kristiansen (Eds.), Social mobilisering-en utmaning för socialt arbete (pp. 119-130). Malmö: Gleerups Utbildning.

Karlsson, M., \& Markström, U. (2013). Idealitet i omvandling? Om det civila samhällets organisationer på psykiatriområdet. Stockholm: Ersta Sköndal Förlag.

Lewis, L. (2014). User involvement in mental health services: A case of power over discourse. Sociological Research Online, 19(1), $1-15$.

Mansbridge, J. (1999). Should blacks represent blacks and women represent women? A contingent, "yes". Journal of Politics, 61(3), 628-657.

Markström, U., \& Karlsson, M. (2013). Towards hybridization: The roles of Swedish non-profit organizations within mental health. VOLUNTAS: International Journal of Voluntary and Nonprofit Organizations, 24(4), 917-934.

Mayer, C., \& McKenzie, K. (2017). '...It shows that there's no limits': The psychological impact of co-production for experts by experience working in youth mental health. Health and Social Care in the Community, 25(3), 1181-1189.

McLaughlin, H. (2009). What's in a name: 'Client', 'patient', 'customer', 'consumer', 'expert by experience', 'service user'what's next? British Journal of Social Work, 39(6), 1101-1117.

Meriluoto, T. (2018). Turning experience into expertise: Technologies of the self in Finnish participatory social policy. Critical Policy Studies, 12(3), 294-313.

Mohanty, S. P. (2000). The epistemic status of cultural identity: On beloved and the postcolonial condition. In P. M. L. Moya \& M. R. Hames-Garcia (Eds.), Reclaiming identity: Realist theory and the predicament of postmodernism (pp. 29-66). Berkeley: University of California Press.

Montenegro, C. R., \& Cornish, F. (2019). Historicising involvement: The visibility of user groups in the modernisation of the Chilean Mental Health System. Critical Public Health, 29(1), 61-73.

Moreira, T., O’Donovan, O., \& Howlett, E. (2014). Assembling dementia care: Patient organisations and social research. Biosocieties, 9(2), 173-193.

Myndigheten för vårdanalys. (2015). Sjukt engagerad-en kartläggning av patient- och funktionshinderrörelsen. Stockholm: Myndigheten för vårdanalys.

Näslund, H., Sjöström, S., \& Markström, U. (2019a). Delivering experiential knowledge: Repertoires of contention among Swedish mental health service user organisations. Nordic Social Work Research. https://doi.org/10.1080/2156857X.2019.1583599.

Näslund, H., Sjöström, S., \& Markström, U. (2019b). Service user entrepreneurs and claims to authority. European Journal of Social Work. https://doi.org/10.1080/13691457.2019.1580249.

Nelson, J., \& Nelson, L. H. (1994). No rush to judgment. The Monist, 77(4), 486-509.

Noorani, T. (2013). Service user involvement, authority and the 'expert-by-experience' in mental health. Journal of Political Power, 6(1), 49-68.

Noorani, T., Karlsson, M., \& Borkman, T. (2019). Deep experiential knowledge: Reflections from mutual aid groups for evidencebased practice. Evidence \& Policy, 15(2), 217-234.

Omeni, E., Barnes, M., MacDonald, D., Crawford, M., \& Rose, D. (2014). Service user involvement: Impact and participation: A survey of service user and staff perspectives. BMC Health Services Research, 14(1), 491-504.

Parsloe, S. M., \& Holton, A. E. (2018). \#Boycottautismspeaks: Communicating a counternarrative through cyberactivism and connective action. Information, Communication \& Society, 21(8), 1116-1133.

Pattadath, B. (2016). Experience as 'expert' knowledge: A critical understanding of survivor research in mental health. Philosophy Psychiatry \& Psychology, 23(3-4), 203-205.

Polletta, F. (1998). Contending stories: Narrative in social movements. Qualitative Sociology, 21(4), 419-446.

Rabeharisoa, V., Moreira, T., \& Akrich, M. (2014). Evidence-based activism: Patients', users' and activists' groups in knowledge society. Biosocieties, 9(2), 111-128.

Restall, G., Cooper, J. E., \& Kaufert, J. M. (2011). Pathways to translating experiential knowledge into mental health policy. Psychiatric Rehabilitation Journal, 35(1), 29-36.

Rose, D. (2014). Patient and public involvement in health research: Ethical imperative and/or radical challenge? Journal of Health Psychology, 19(1), 149-158.

Rose, D. (2016). Experience, madness theory, and politics. Philosophy Psychiatry \& Psychology, 23(3-4), 207-210.

Rose, D., \& Lucas, J. (2007). The user and survivor movement in Europe. In M. Knapp, D. McDaid, E. Mossialos, \& G. Thornicraft (Eds.), Mental health policy and practice across Europe (pp. 336-355). Maidenhead: McGraw Hill Open University Press.

Rothstein, B. (1992). Explaining Swedish corporatism: The formative moment. Scandinavian Political Studies, 15(3), 173-191.

Sanati, A., \& Kyratsous, M. (2015). Epistemic injustice in assessment of delusions. Journal of Evaluation in Clinical Practice, 21(3), 479-485.

Scott, J. W. (1991). The evidence of experience. Critical Inquiry, 17(4), 773-797.

Selznick, P. (1949). TVA and the grass roots: A study in the sociology of formal organization. Berkeley: University of California Press.

Siebers, T. (2006). Disability studies and the future of identity politics. In L. M. Alcoff, S. P. Mohanty, M. Hames-Garcia, \& P. M. L. Moya (Eds.), Identity politics reconsidered (pp. 10-30). New York: Palgrave Macmillan.

Smith, D. (1988). The everyday world as problematic: A feminist sociology. New York: Open University Press.

Stone-Mediatore, S. (2000). Chandra Mohanty and the revaluing of "experience". In U. Narayan \& S. Harding (Eds.), Decentering the center: Philosophy for a multicultural, postcolonial, and feminist world (pp. 110-127). Bloomington: Indiana University Press.

Storm, M., \& Edwards, A. (2013). Models of user involvement in the mental health context: Intentions and implementation challenges. Psychiatric Quarterly, 84(3), 313-327.

Sweeney, A., \& Wallcraft, J. (2010). Quality assurance/monitoring of mental health services by service users and carers. Leuven: WHO

Telford, R., \& Faulkner, A. (2004). Learning about service user involvement in mental health research. Journal of Mental Health, 13(6), 549-559.

Thornicroft, G., \& Tansella, M. (2005). Growing recognition of the importance of involvement in mental health service planning and evaluation. Epidemiologia e Psichiatria Sociale, 14(1), 1-3.

Tritter, J. Q., \& McCullum, A. (2006). The snakes and ladders of user involvement: Moving beyond Arnstein. Health Policy, 76(2), $156-168$

Voronka, J. (2015). Troubling inclusion: The politics of peer work and 'people with lived experience' in mental health interventions. Toronto: University of Toronto.

Voronka, J. (2016). The politics of 'people with lived experience': Experiential authority and the risks of strategic essentialism. Philosophy Psychiatry \& Psychology, 23(3-4), 189-201.

Publisher's Note Springer Nature remains neutral with regard to jurisdictional claims in published maps and institutional affiliations. 